\title{
EDITORIAL
}

\section{When the past is present}

\author{
Albina R. Torres, ${ }^{1}$ Daniel L.C. Costa, ${ }^{2}$ Eurípedes C. Miguel ${ }^{2}$ \\ ${ }^{1}$ Faculdade de Medicina, Universidade Estadual Paulista Julio de Mesquita Filho (UNESP), Botucatu, SP, Brazil. ${ }^{2}$ Faculdade de Medicina, \\ Universidade de São Paulo (USP), São Paulo, SP, Brazil.
}

An impressive article by Steinberg et al., ${ }^{1}$ published in this issue of Revista Brasileira de Psiquiatria, provides an insightful comparison between current diagnostic criteria for obsessive-compulsive disorder (OCD) and Emil Kraepelin's conceptualization of the condition. Kraepelin (18561926), who was one of the most influential German psychiatrists of all times, described the condition in the 8th edition of his Textbook of Clinical Psychiatry, published at the beginning of the 20th century, and his contributions to nosology transformed the specialty.

Kraepelin's critical view of "obsessive neurosis" (ON) was based on his systematic clinical approach and on previous contributions by other renowned psychiatrists, including Westphal, von Krafft-Ebing, Griesinger, Thomsen, Löwenfeld, du Saulle, and Janet.

Steinberg et al. should be commended for their initiative of carefully reading and interpreting the 95-page-long chapter on $\mathrm{ON}$, and then drawing a parallel with each OCD criterion listed in the DSM-5, including aspects related to symptomatology, etiology, nosology, and differential diagnosis. Interestingly, the authors identified more similarities than differences between Kraepelin's view of $\mathrm{ON}$ and the current definition of the disorder. Indeed, his concept of $\mathrm{ON}$ is considerably modern, for several reasons. Concerning the main symptoms, Kraepelin described the close relationship between obsessive and compulsive manifestations, but also the existence of "pure" obsessions, with no related compulsive acts (e.g., musical obsessions); compulsions preceded not by typical obsessive fears, but by other motivations (currently described as "sensory phenomena") 2 ; compulsive acts related to obsessive fears in an unclear or bizarre manner; persistent compulsions performed automatically, even when the fear of unwanted events is no longer present or relevant; mental or covert rituals, such as calculating and brooding ${ }^{3}$; subclinical symptoms in healthy people; and the considerable impact of ON on occupational and social activities.

Several aspects of the psychopathology of OCD remain controversial, including the existence of a pure obsessional type. Even though DSM-5 criteria, in line with the

Correspondence: Albina Rodrigues Torres, Departamento de Neurologia, Psicologia e Psiquiatria, Faculdade de Medicina de Botucatu (FMB), Universidade Estadual Paulista Julio de Mesquita Filho (UNESP), Av. Prof. Mário Rubens G. Montenegro, $s / n^{\circ}$, Distrito de Rubião Jr., CEP 18618-687, Botucatu, SP, Brazil.

E-mail: albinatorres@gmail.com

Epub Oct 022017. behavior theory, assume a functional relationship between obsessions and compulsions ("attempts to ignore or suppress the obsessions or to neutralize them with some other thought or action"), an OCD diagnosis is allowed for patients presenting either obsessions or compulsions alone.

Among more typical manifestations of $\mathrm{ON}$, Kraepelin included hoarding symptoms, dysmorphophobic and hypochondriac ideas, and tics. The two first items are listed in the Obsessive-Compulsive and Related Disorders chapter of the DSM-5 as independent diagnostic entities (hoarding disorder [HD] and body dysmorphic disorder [BDD], respectively), while hypochondriasis is not. Notably, hypochondriasis will be included among OCD-related disorders in the ICD-11, ${ }^{4}$ due to its close relationship with $\mathrm{OCD}$ and BDD. The nosological status of hoarding manifestations has been much debated in recent years. Even though they may indeed constitute a primary condition, they may also be a part of the OCD phenotype, usually driven by obsessive concerns related to contamination, obsessive doubts, feelings of incompleteness, or "not-just-right" experiences. ${ }^{5}$ Unlike patients with HD, those with OCD usually see little value and do not really want the objects they hoard, which can be fairly bizarre. ${ }^{5}$ Interestingly, the hoarding symptoms that Kraepelin described in ON were clearly motivated by obsessive fears, and frequently involved body parts, such as nails or hair. Finally, tic disorder is both an independent entity and an OCD specifier in the DSM-5 (tic-related OCD), associated with male sex, sensory phenomena, and specific comorbidities. $^{3}$ According to Kraepelin, unlike obsessive-compulsive acts, tics are just impulsive urges or "sparse compulsive drives," with no clear motivation. Nevertheless, some complex tics are hardly distinguishable from compulsions, and a continuum may exist between tics and compulsions. ${ }^{2}$

Concerning insight, another specifier in the DSM-5 (i.e., good/moderate, poor, or absent), Kraepelin clearly stated that not all patients had good insight and that decreased insight was related to both increased illness severity ${ }^{3}$ and specific symptom contents, particularly hypochondriac obsessions, in which a clear understanding could be jeopardized by "fearful excitation."

Regarding external boundaries, Kraepelin did a great job disentangling ON from mania, depression, schizophrenia and other psychotic disorders (e.g., differentiating obsessions from delusions and thought insertion), eating disorders, hysteria, and obsessive personality ("egosyntonic expression of one's will"). Trichotillomania and skin picking, two other OCD-related disorders in the DSM-5, 
were considered by him, along with nail biting and thumb sucking, as simple drives or impulsive acts not particularly related to ON. Notably, he postulated that paraphilias, impulse-control and conduct disorders were opposite to $\mathrm{ON}$, as they were expressions of an inner drive or will, involving satisfaction, denial of negative consequences, and no regret.

Kraepelin described an early clinical onset of $\mathrm{ON}$, usually in adolescence or childhood, suggesting an "inhibition in development," in line with the contemporary view of OCD as a developmental disorder. Moreover, he denied a predisposition of patients with ON to paranoia, schizophrenia, or manic-depressive psychosis. Finally, he acknowledged that although $\mathrm{ON}$ was a discrete nosological entity, obsessive-compulsive manifestations could be present in several other mental illnesses.

This careful comparative analysis of past and current conceptualizations of OCD highlights how complex and challenging this disorder is. Despite much research conducted in recent decades, many questions remain unanswered regarding the phenomenology, diagnostic boundaries, and etiology of OCD. No wonder Kraepelin needed 95 pages to describe this highly heterogeneous and intriguing mental illness.

This brilliant article ${ }^{1}$ fills a gap in psychiatric literature, as historical studies on OCD are scarce. The authors concluded that most of what we know about OCD today, Kraepelin knew more than a century ago, based on his incredible observational skills. Similar to Kraepelin's approach to his patients, Steinberg et al. studied Kraepelin's view of ON with true interest, full attention, and profound reflection. Thus, this is a rare contribution in these (sad) times of diagnoses based on symptom checklists, with little attention to or interest in the essential psychopathological underpinnings of psychiatric disorders. ${ }^{6}$

\section{Disclosure}

The authors report no conflicts of interest.

\section{References}

1 Steinberg H, Carius D, Fontenelle LF. Kraepelin's views on obsessive neurosis: a comparison with DSM-5 criteria for obsessive-compulsive disorder. Rev Bras Psiquiatr. 2017 Mar 13:0. doi: 10.1590/15164446-2016-1959. [Epub ahead of print].

2 Miguel EC, do Rosário-Campos MC, Prado HS, do Valle R, Rauch SL, Coffey BJ, et al. Sensory phenomena in obsessive-compulsive disorder and Tourette's disorder. J Clin Psychiatry. 2000;61:150-6.

3 Shavitt RG, de Mathis MA, Oki F, Ferrao YA, Fontenelle LF, Torres AR, et al. Phenomenology of OCD: lessons from a large multicenter study and implications for ICD-11. J Psychiatr Res. 2014;57:141-8.

4 Stein DJ, Kogan CS, Atmaca M, Fineberg NA, Fontenelle LF, Grant $\mathrm{JE}$, et al. The classification of obsessive-compulsive and related disorders in ICD-11. J Affect Disord. 2016;190:663-74.

5 Pertusa A, Frost RO, Mataix-Cols D. When hoarding is a symptom of OCD: a case series and implications for DSM-V. Behav Res Ther. 2010;48:1012-20.

6 Stanghellini G, Broome MR. Psychopathology as the basic science of psychiatry. Br J Psychiatry. 2014;205:169-70. 